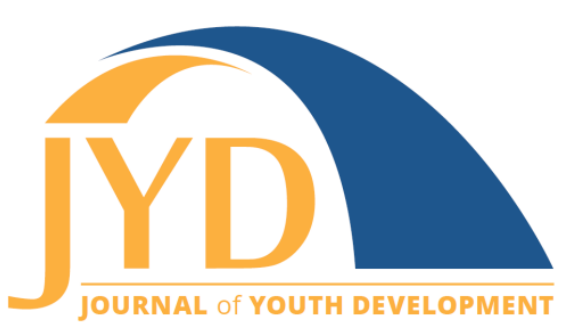

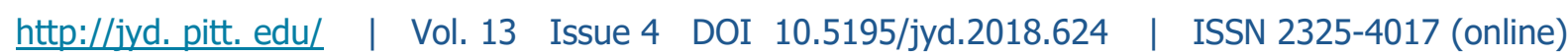

\title{
Reframing "Failure" in Making: The Value of Play, Social Relationships, and Ownership
}

\author{
Jean J. Ryoo \\ University of California, Los Angeles \\ jeanryoo@ucla.edu \\ Linda Kekelis \\ STEM Next Opportunity Fund \\ Ikekelis@gmail.com
}

\begin{abstract}
Building on grit and growth mindset literature, the "maker mindset" celebrates persistence through failure as key to inspiring creativity in making education. Yet, moving beyond examinations of individual persistence and assumptions that all people have the same wealth of resources to persevere, when is it worthwhile to work through challenging projects? What supports are necessary for youth to feel safe working through challenges in science, technology, engineering, math, and computing $(S T E M+C)$ activities? Using sociocultural theory as a lens, this ethnographic study analyzed observation field notes, videos, photos, student work, and interviews from an after-school making program for high school girls during the 2014-15 school year. Through a comparison of 2 groups-one that persisted through challenging moments and one that did not-this paper reveals the centrality of playfulness, teamwork, and ownership of projects in order to persist through challenges that arise in inquiry-based projects.
\end{abstract}

Key words: making, failure, persistence, play, sociocultural theories of learning, collaborative learning, project ownership

\section{Introduction}

\section{Celebrating Failure With Grit and Growth Mindset in the Maker Movement}

From education to business, "failure" has shifted from being anathema to success to the key to improving learning for all (Babineaux \& Krumboltz, 2013; Basulto, 2012; Kapur, 2008, 2014). Both educational scholars and corporate CEOs suggest failure leads to better outcomes for

\footnotetext{
(cc) $\mathrm{EY}$ New articles in this journal are licensed under a Creative Commons Attribution 4.0 License. This journal is published by the University Library System, University of Pittsburgh and is cosponsored by the University of Pittsburgh Press. The Journal of Youth Development is the official peer-reviewed publication of the National Association of Extension 4-H Agents and the National AfterSchool Association.
} 


\section{Reframing "Failure" in Making}

students and startups. This celebration of failure sits at the center of the maker movement (Martin, 2015).

While we have been "making" objects since the dawn of humankind, the maker movementmade up of do-it-yourself tinkerers and inventors of all ages-has been spreading worldwide since the 2006 Maker Faire in San Mateo, California. It embraces a culture of learning-throughdoing within peer-led environments where tools previously limited to the elite (e.g., 3D printers) are accessible to all (Blikstein, 2013; Vossoughi \& Bevan, 2014). Increasingly, educational leaders and researchers view making as a means to broaden participation in science, technology, engineering, math, and computing (STEM+C) fields (Kafai, Fields, \& Searle, 2014; Sheridan et al., 2014).

Making serves as a means for learning STEM+C content and practices as students design and create projects (from cardboard pinball machines that require an understanding of circuitry and physics, to self-zippering jackets programmed to sense external temperatures) (Bevan, Ryoo, \& Shea, 2017; McNeill, Katsch-Singer, \& Pelletier, 2015; Ryoo \& Kekelis, 2016). Furthermore, making provides opportunities to value learners' expertise and cultural practices in ways that traditional STEM+C educational environments have not typically welcomed (Vossoughi, Hooper, \& Escudé, 2016).

Yet as students create making projects, they meet with frustration when plans do not result as originally conceived (Blikstein, 2013; Martinez \& Stager, 2013). These challenges are celebrated as "failures" that inspire learning new skills. Drawing on growth mindset (Dweck, 2006) and grit (Duckworth, Peterson, Matthews, \& Kelly, 2007), the movement claims that "tolerat[ing] risk and failure" is what results in the "maker mindset" and creativity (Dougherty, 2013, p. 9).

Grit is defined as individual perseverance for long-term goals despite failure (Duckworth et al., 2007), and growth mindset as seeing challenges as opportunities to acquire new skills despite risk of failure (Dweck \& Leggett, 1988; Dweck, 2006). Both concepts have gained traction as solutions to educational achievement gaps. The maker movement champions these ideas toward encouraging youth to persist through challenging projects.

\section{Challenging Grit and Growth Mindset Toward Reframing "Failure"}

While there is much to be gained from learning from one's mistakes, grit and growth mindset are not the most meaningful lenses with which to understand persistence in STEM+C making 


\section{Reframing "Failure" in Making}

projects. First of all, due to its association with judgments of intellectual ability in today's highstakes testing, many caution against the use of the word "failure" as a focal point (Kekelis \& Ryoo, 2015; Martin, 2015; Martinez \& Stager, 2013). In making contexts, we find it more productive to emphasize iteration over failure while working through design challenges (Ryoo, Bulalacao, Kekelis, McLeod, \& Henriquez, 2015; Vossoughi, Escudé, Kong, \& Hooper, 2013). Secondly, scrutiny of the original grit studies finds issue with claims that individual grit leads to success: there is a lack of causality between grit and achievement, and problems with bias in self-report surveys (Credé, Tynan, \& Harms, 2016; Kohn, 2014; Rose, 2015). Others were unable to replicate growth mindset results (Li \& Bates, 2017) and demonstrated that educators receiving growth mindset training had little to no impact on their students (Rienzo, Rolfe, \& Wilkinson, 2014).

Furthermore, focusing narrowly on individual attitudes as explanations for academic failure or success ignores how larger social, cultural, and historical systems create inequitable structures that impact students (Rustin, 2016). Grit and growth mindset are personal qualities that may be difficult to enact in light of factors such as poverty or institutional racism. Sometimes it is wiser to give up rather than risk failure, especially when one is not in a position of privilege to try again. We must recognize when persistence can be useful or counterproductive, while understanding that grit and growth mindset should be part of an array of qualities to support in youth (Kohn, 2014, 2015; Rose, 2015). This is especially true in STEM+C contexts where underrepresented youth may feel unwelcome or unconfident.

This paper offers a different approach to thinking about persistence. Sociocultural theories are employed as an alternative framework to grit and growth mindset for understanding persistence among young women creating projects in a STEM+C making space through the following research questions:

- Beyond examinations of individual perseverance, what happens when collaborative groups face challenges?

- How and when do youth choose to persist through such challenges, if at all?

- How do challenges in groups influence individuals' confidence and persistence in $\mathrm{STEM}+\mathrm{C}$ ?

After describing our theoretical framing, research context, and methods, we explore two different groups' trajectories through challenges-persisting and giving up-while creating Maker Faire projects. This is followed by an analysis of factors impacting girls' decisions to persist or not, and recommendations for designing educational programs. 


\section{Reframing "Failure" in Making}

\section{Examining Persistence Through Sociocultural Theories of Learning}

Grit and growth mindset studies typically attend to measuring individual perspectives-through surveys, for example-divorced of the social contexts in which learning occurs. This study seeks a different approach to understanding perseverance, by examining persistence when individuals come into contact with other people, ideas, and practices.

Sociocultural theories of learning guide this study's exploration of persistence, focusing on how learning occurs through social interactions between people, ranging from expert to novice, and not in a one-way direction from adult to child (Vygotsky, 1978). Learners bring personal knowledge (and history) to educational contexts imbued with cultural meaning through the tools used to learn and the ways people engage with others (Lave \& Wenger, 1991; Rogoff, 1994; Wertsch, del Rio, \& Alvarez, 1995). Explicit and implicit rules of behavior guiding the way people interact (e.g., expectations about how students should raise their hands in the classroom), power dynamics between individuals in a space (impacted by age, race/ethnicity, gender, ability, etc.), and roles people take on in a learning community (e.g., as the classroom expert) also impact how and what one learns (Cole \& Engestrom, 2007).

This sociocultural perspective is important when examining persistence, not only because it is valuable to look beyond individual self-reports, but also because of the type of analysis this lens affords. When the grain-size moves beyond the individual to include sociocultural surroundings, other factors impacting decisions to persevere become visible. For example, a student may say she chose not to complete a science lab because of a lack of interest, but looking beyond her statement may reveal how an uncooperative lab partner stymied her participation, or engineering projects at home made the science lab seem unchallenging in comparison. Looking at the sociocultural context of learning allows us to attune to the power dynamics impacting whether a learner feels welcome to pursue challenging problems. We believe that this is particularly important to consider in this study's context: an after-school program created to inspire learning for young women underrepresented in STEM+C.

\section{Study Context: An After-School Making Program for Girls}

Techbridge Girls is a free, year-long, after-school program serving girls from communities underrepresented in STEM+C. After-school educators collaborate with in-school teachers to offer hands-on learning for approximately 2-3 hours a week. In the high school program under study, girls created making projects addressing a social problem or interest to present at the 


\section{Reframing "Failure" in Making}

2015 San Mateo Maker Faire. There were 25 youth in grades 9 through 12 enrolled, of whom 40\% were White, 20\% Asian/Pacific Islander, 20\% Latina, 8\% African American, and 12\% multi-ethnic. Approximately half attended Techbridge Girls in middle school. During the first semester, girls engaged in open-ended activities introducing them to programming Arduino microcontrollers, an open-source electronics platform that can be used to build interactive objects for sensing or controlling the physical world. In the second semester, girls designed and created Maker Faire projects using Arduino.

Educators supported inquiry-based learning that encouraged young women to create projects of their own design. Projects iteratively built on new skills, and educators prioritized playfulness so that the program did not feel like "school." As such, educators often began program with icebreaker activities to support friendships between girls from different grade levels or schoolday cliques.

\section{Methods}

This paper describes the result of a 3-year research-practice partnership in which researchers and educators came together to collaboratively identify and research key challenges (Coburn, Penuel, \& Geil, 2013). Data sources-including field notes, audio/video recordings, student projects, and interviews-were collected using interpretive participant observation methods (Erickson, 1998) that privileged students' and teachers' understandings of experiences and interactions. Researchers collected 68 observation hours during 2014-15 program meetings and Maker Faire.

Data sources were coded using the constant comparative method (Glaser \& Strauss, 1967; Taylor \& Bogdan, 1998). The first round involved surfacing codes grouped into categories, informed by joint sense-making of field notes with Techbridge Girls educators and CEO. The second read of data compared codes within categories to better understand emergent themes. Codes were considered in relation to the sociocultural theories informing our understanding of learning and pedagogy.

The coding scheme included primary codes such as "pedagogical action" to denote teaching moves, or "student agency" to mark when students took initiative on their projects. Sub-codes included items such as "facilitate collaboration" for "pedagogical actions," or "student changes design direction" as types of "student agency." Outlier codes included the sub-code "tension" under the parent code of "teamwork." 
In this paper, we focus on two groups in the program: one that struggled yet persisted, and one that struggled but gave up when faced with project challenges. Shared variables between the groups included: (a) use of computing tools, (b) complexity of projects, (c) group size (more than 2 people), and (d) total observation hours. Yet the groups were different in grade level, prior experience with the program, and the persistence they demonstrated through challenges. These similarities and differences served as valuable comparison points across the groups in order to inform broader understandings for how sociocultural dynamics relate to persistence (Mitchell, 1984).

\section{Findings}

The following contrasting cases illuminate how sociocultural dynamics impacted decisions to persist or give up in the face of challenge. Case \#1 involved Nina, Quian, Chloe, and Luisa who toiled for months to create an interactive sound and light project called Musicbox. Musicbox was an adult-sized cardboard box with sound-reactive LEDs along the interior that lit up when musical notes were played on conductive copper tape "piano keys" connected to an Arduino and speaker. Quian and Chloe ( $11^{\text {th }}$ graders; immigrant Chinese and biracial Asian/White respectively) were friends before joining this team. They met in a middle school Techbridge Girls program and played in orchestra together. Nina ( $11^{\text {th }}$ grade Latina) was not previously friends with her teammates and was new to the program. Luisa (12 ${ }^{\text {th }}$ grade Latina) attended Techbridge Girls throughout high school but had never collaborated with this team before. The girls bonded over a shared love of music and desire to teach people about musical composition.

Case \#2 involved three ninth graders. Jessica and Stella were White and met in middle school, but didn't become friends until high school. Camille was African American and belonged to a different friend group. Camille's father was a high school teacher and encouraged her to join Techbridge Girls. Jessica joined because she enjoyed learning science in Techbridge Girls in fifth grade. Stella was new, encouraged by her mother to join. Jessica and Stella came together to create Brightstyle - clothing with LEDs that changed color in reaction to sound. Camille was absent when groups were formed. Rather than work alone or with older girls, Camille asked Jessica and Stella if she could join their group.

These contrasting cases offer a unique opportunity to explore the sociocultural factors impacting whether or not girls persisted through STEM+C challenges. More specifically, how perseverance was impacted by: (a) playfulness that invited collaboration and out-of-the-box 


\section{Reframing "Failure" in Making}

thinking; (b) teamwork that supported girls feeling safe not knowing immediate answers; and (c) how ownership of projects led to feeling proud about working through challenges and successes.

\section{Case \#1: Playfulness, Teamwork, and Feeling Ownership to Overcome Challenges}

Nina, Quian, Chloe, and Luisa struggled for over seven hours with an Arduino microcomputer to get wires in their Musicbox project to react to touch. Although frustrated, the girls persisted, generating numerous ideas to solve the technical challenge. Key themes that emerged while coding Case \#1 data are described below.

\section{Playfulness and Persistence}

When trying to get wires to generate sound through touch, this group playfully riffed off of each other's ideas, ping-ponging observations back and forth through interspersed laughter. Nina declared, "Something was happening! And now it's not." Quian joked, "Maybe we broke it" and Nina protested with a smile, "We did not break it!" Quian clarified with a grin, "Maybe we shortcircuited it" as Chloe noted with a laugh, "Maybe [the note] was too high for it!" Quian continued fiddling with the wires as Nina suggested, "I think it just needs to be attached to copper plating" and Luisa asked, "Do you have copper tape? It's A-okay!" The girls laughed at her enthusiasm. Suddenly, the wires began croaking to Quian's touch and Luisa exclaimed, "It's like a frog!" and they laughed again.

Such serious yet silly banter was common in this group. They regularly engaged each other's ideas by asking questions, sharing alternative perspectives, or confirming what was shared, while making each other smile. For example, when testing that piece of copper suggested by Nina, the girls hypothesized whether it was too thick to produce consistent reactions to touch (Chloe), if the wires may be faulty (Nina), if bending the copper impacted sound (Luisa), or if the copper's temperature mattered (Chloe), while simultaneously laughing when Luisa didn't hear a sound or when the copper failed to react to Chloe's touch. Quian joked about Chloe's lack of conductivity as Luisa laughed about the copper having a "sweet spot."

But the design and build process was not $100 \%$ fun. The girls would exclaim: "This is so frustrating!" or "I'm done!" However, the girls persisted, and at the end of the year, all four considered each other good friends after laughing together through this project. 


\section{Reframing "Failure" in Making}

Importantly, playfulness was not a social practice limited to this group. The educators often joked with the girls. One teacher was known for using puns. The other would do things like pretend to "steal" Case \#1's speaker, slipping it into his pocket as he looked elsewhere, even though the girls were watching him and already gave him permission to experiment with their materials. Playfulness was regularly observed in the larger community.

\section{Valuing Teamwork and Feeling Safe Saying "I Don't Know"}

The girls worked well as a team: they never hesitated sharing materials and computers while welcoming each other's input, such as taking on Nina's suggestion to test with copper or Chloe's suggestion to forego soldering in favor of attaching materials with tape. They also valued each other's skills. Nina was never too proud to ask Quian to strip wires for her nor was Chloe afraid to confirm questions about computer code with Nina.

In interviews, the girls described valuing teamwork: Quian and Chloe mentioned that their project forced the team to "disagree," and this was "exciting." Rather than seeing arguments as negative, the girls appreciated debate as a way of "contributing something" and feeling pride in one's ideas. Luisa similarly noted that the team didn't always agree on how to address challenges, but "it's definitely very good to have all those differing [ideas]...it's more exciting...it was a good group."

The girls saw educators as valuable team members as well. Nina appreciated when adults worked "side by side" with them, "try[ing] to figure out what the problem exactly was." Luisa agreed that when teachers "put themselves on equal position[s]...not talking down to us," she felt supported to work through challenges.

Within this teamwork context, the girls did not fear saying "I don't know." For example, when one teacher asked the group, "What's supposed to happen with the copper?" Luisa did not hesitate to say, "I don't know." Later, Luisa asked Chloe, "How does this work?" to which Chloe laughed saying, "Nobody knows." The educators modeled saying "I don't know" as part of the learning process, suggesting this was a valued social norm. For example, the teacher described above never pretended to know more than his students, and was willing to ask students to teach him new ideas. He regularly borrowed materials to learn alongside the girls about how they worked. 


\section{Reframing "Failure" in Making}

Yet, the girls never stopped at "I don't know" as they persisted until their prototype created sound to touch, and they were eventually able to explain how the project functioned. This willingness to say "I don't know" was related to their shared definitions of the making process more generally as something that is "never completely done" and involves "a lot of things that don't work and trying it again. A lot of frustration sometimes, but it's worth it" (Luisa). Making was described as a "constant process" of "chang[ing] something and then test[ing] it ...do projects ever truly end?" (Nina). Chloe and Quian agreed. Thus, "I don't know" was described as an inevitable aspect of the "constant" testing and retesting process of making.

\section{Ownership of Projects $=$ Ownership of Challenges}

The girls explained that projects were worth persisting through because of the collaborative ownership they felt over the ideas and effort. Quian shared that she felt committed to working through frustrating challenges because "we came up with something of our own, and we want[ed] to do it cause it [was] our idea." Chloe noted that the challenges were "exciting" because the problems were self-created: "we know it's our fault so I feel like it's better than having it not be your fault and having to struggle with that." Note in particular the use of "we" vs. "I" in these statements, acknowledging the effort as shared problem-solving and ownership.

Educators supported this ethos of project ownership, as students were encouraged to create projects of their own design for every activity. Educators shared examples of projects they were working on too, modeling the spirit of self-motivated invention. As girls worked on projects, teachers never solved problems for them, even if they knew solutions. Instead, educators asked questions to promote girls' thinking as they struggled, or pointed them to each other or online resources for help.

\section{Case \#2: Struggling to Persist Together}

Not all groups worked as productively through challenges. Jessica and Stella worked well with each other, but not with their teammate Camille. Educators tried to encourage them to collaborate, but their efforts could not overcome the group's dynamics.

For example, when the girls struggled to get their LEDs to respond to a line of Arduino code, they turned to Edward (a teacher) for help. Noticing Camille sat at a separate computer, Edward noted, "we can figure that out together . . . " to which Stella replied (ignoring his comment), "I'm guessing, it's just like . . . " and Jessica finished her sentence: "batteries...or 


\section{Reframing "Failure" in Making}

the laptop. Wouldn't the laptop work as a power supply?" Stella added, "'cause that's what we're coding on." Edward suggested trying other power sources such as a 9-Volt battery, then repeated, "so if you can work on it together..." Stella replied, "cool" but continued to work apart from Camille. Edward asked a third time for the girls to collaborate before moving on to support another group. Yet only Camille moved closer to Jessica and Stella.

The girls' interactions continued this way all semester. For example, when Stella and Jessica were looking through example code, Camille made an effort to engage her partners, asking, "So do we just copy that [pointing to Jessica and Stella's computer screen] onto the Arduino application?" Stella said, "Well it depends. I may be wrong. But since we have a button, I don't think that this will be the exact same code." Camille turned to her laptop saying, "Wait how did...oh, never mind" as she cut herself off. Camille angled Jessica and Stella's laptop so she could see it better, but they made no effort to make space for Camille. Camille began comparing their code with what she found, as Jessica and Stella started chatting about an unrelated topic.

At another point, when Camille tried to see her partners' laptop screen, Jessica said, "Take it." Camille joked about taking it home, but Jessica took her seriously and replied, "Oh, I don't know." Camille said, "No, I’m kidding." Jessica replied flatly, "Oh ..."

Interestingly, interviews with Stella and Jessica revealed that they shared many similar beliefs with Case \#1's team regarding the power of collaboration and social relationships to overcome challenges. Stella shared that she didn't feel "stress" creating a Maker Faire project because "all the people [in the program] were really nice" and because she could "choose what to do." Jessica agreed that when there "weren't really instructions" and she could choose her own project direction, she felt excited to "figure it out." Furthermore, Jessica and Stella were often observed being playful together, but never with Camille. During the first semester, Jessica and Stella created a Harry Potter book together that screamed when opened to the page where Voldemort (an evil character) first appears. The project itself was playful, and the girls laughed often while learning new skills together. Yet this playfulness did not transfer to their interactions with Camille.

Ultimately, Jessica and Stella often turned to adults for answers rather than persist with Camille. For example, when Jessica declared, "I don't know what to do now!" and Stella agreed, "I think we should ask Edward," Camille didn't want to give up and, searching the Internet, 


\section{Reframing "Failure" in Making}

said, "There should be steps." Jessica responded, "I prefer asking Edward" while ignoring Camille's efforts. By the time of the Maker Faire, the girls were not yet done with their project.

At the end of the semester, in order to understand the group's dynamics, Jessica and Stella were asked how their group was formed. Stella remained uncomfortably silent while Jessica explained: "[Camille] needed a group, and we had a fun idea. So she joined." There was no description of welcoming Camille or inviting her to the team. When asked if they got to know Camille through the project, Stella, again, had no reply while Jessica stated, "I already sort of knew her" because they shared a school-day class. Neither girl wanted to expand on these responses. Camille did not want to be interviewed and chose not to help present the group's project at Maker Faire.

And how did program educators respond to this group's interactions? In interview, one teacher reflected: "I don't think we were necessarily looking at the problem as a 'these girls are not getting along' problem and more of a 'these girls aren't going to complete their project' problem" and thus interventions were aimed at helping the girls finish their project instead of improving their social dynamics. This teacher regretted that he didn't make greater efforts to address the group's relationships, adding: "I didn't come to a lot of this understanding about how important group dynamics were until afterward" and that, in retrospect, supporting girls to "really care about each other and have a sisterhood" should have been his focus, more than having finished projects for Maker Faire.

\section{Discussion}

In making sense of Case \#1's persistence through challenges, the findings above show how sociocultural dynamics-playfulness; teamwork; and willingness to share ideas, lack of knowledge, and ownership-propelled the girls to work through frustrations.

More specifically, the girls' playfulness not only cemented their team-based friendships, but also made frustrating challenges ultimately enjoyable enough to persist through. Despite Chloe and Luisa expressing annoyance with the project, they remained engaged with the challenges and their teammates, while laughing about the frustrations in their very next breaths.

The girls' testimonies about the value of struggling through ideas as a team, even with disagreements, reflect how collaboration was an important force behind the girls' persistence. The teamwork norms of the group created a playful space where the girls felt comfortable 


\section{Reframing "Failure" in Making}

sharing ideas (regardless of whether they were "right"), while also being willing to say, "I don't know." This is notable since most people, and especially young women in STEM+C learning contexts, are unlikely to admit that they do not know the answer, unless they feel unconcerned about judgment (Jovanovic \& King, 1998; Pollack, E., 2015; Shapiro \& Williams, 2012).

Teachers were also instrumental in creating a space where the girls could come up with shared definitions of making as a process that requires the constant testing of ideas (with projects never ending) in which "I don't know" was a necessary step toward project solutions.

Finally, the girls in Case \#1 voiced how persisting through challenges was influenced by a feeling of ownership: of both the project ideas and project challenges. Challenges were worth persisting through when ideas and effort were both self-generated and collaborative.

Case \# 2 provided a contrast to Case \# 1 in which sociocultural dynamics negatively impacted persistence, and may have influenced Camille's decision to avoid Maker Faire and a final project interview.

While Case \#2 was an outlier in the program-where all other groups demonstrated caring relationships and persistence-we feel vulnerable sharing their story that exposes program challenges and unresolved questions we wish we addressed in the moment. Yet, we feel a sense of urgency in bringing attention to Case \#2 because of the lessons we learned as both researchers and practitioners.

First of all, from a learning theory perspective, Case \#2 showed how much can be misunderstood if one were to analyze project success based on individual actions and words alone. If we ignored the group's sociocultural dynamics, we might have thought Jessica and Stella were model makers because they were willing to celebrate an unfinished project at Maker Faire. They spoke about loving their project, team and program, and persisting because they got to create a project of their own design. Similarly, looking at Camille divorced from her sociocultural learning context, one might think she was uninterested in STEM+C because she didn't show up at Maker Faire or gush about loving the program in an interview.

Yet a closer look at the group's social dynamics reveals how Jessica and Stella's actions did not always match their words, and how Camille's disengagement was not necessarily due to disinterest in STEM+C or lack of growth mindset. More importantly, concluding that Camille was not interested in STEM+C and didn't have enough grit would not only be wrong, but would also 


\section{Reframing "Failure" in Making}

add to a dangerous misperception of women of color as incapable of pursuing STEM+C, when in fact, there are sociocultural and institutional barriers impeding their progress (Kenney, McGee, \& Bhatnagar, 2012).

Relatedly, Camille tried (unsuccessfully) to connect with her team many times. She first asked a question about their code, and then began asking another question in search for a solution. But her first question was brushed off (Stella suggested Camille's idea wasn't appropriate), and Camille stopped herself midway through her second question, as if afraid she would be dismissed again. Camille continued her inquiry alone, while Stella and Jessica waited for adult assistance. And while Stella and Jessica were playful with one another, Camille's effort to joke with Jessica fell flat. Jessica didn't understand Camille's joke about taking the project laptop home, stunting playfulness that could have helped the group persevere through challenging moments together, as was true for Case \#1.

And thus Jessica and Stella often turned to adults for help rather than persisting through challenging problems with Camille. Their lack of interview detail about working with Camille suggested a discomfort with their partner that may have been too difficult to explain with an adult in an interview. Camille's respective silence suggests this was true for her as well.

Importantly, the teacher's reflection about wishing he had focused more on their relationship as a team rather than the progress of their project for Maker Faire illuminates how the educators, in retrospect, also felt that sociocultural dynamics were central to students' abilities to learn and persist through challenges.

Of course, limitations exist in comparing these two cases. More specifically, the lack of interview data for Camille as well as the differences in the ways the teams formed impact the conclusions we can draw. However, Camille's reticence and Jessica and Stella's body language in relation to their silence during the interview were as important as the words that were uttered, especially when analyzed in relation to observation data of their project interactions. And while we could have pushed the girls to talk about their tensions, we do not believe it would have been ethical to do so because they clearly felt uncomfortable talking about their project relationships. Furthermore, we did not want the limitation of Camille's missing interview to prevent deeper investigation into the challenges experienced by Case \#2. Their tensions are all too common across after-school programs, yet are rarely shared in publications by those (such as ourselves) who feel responsible for such tensions. 


\section{Conclusion}

At its best, making offers a context for youth-directed learning that can be challenging and engaging. For youth underrepresented in STEM+C fields-who cannot control obstacles such as institutional sexism, racism, or poverty impacting their academic pathways-making experiences in safe learning conditions can be life changing (Calabrese Barton, Tan, \& Greenberg, 2017). Yet as the contrasting cases illustrate, neither making nor individual grit alone encourage persistence to solve challenging problems or learn STEM+C skills. Social relationships and program culture powerfully influence how and why youth work through frustrations.

We believe our findings have important implications for program practice. More specifically, programs should not ease up on activities that support building student community, even when deadlines loom or projects gain momentum. Learning from this particular experience, subsequent Techbridge Girls programs have incorporated more opportunities for youth to get to know each other.

Secondly, while the maker movement celebrates failure and highlights the promise of STEM+C learning, Case \#2 reveals what can happen when projects do not go as planned. Since most making projects involve pursuing ideas without a blueprint, there is greater potential to run into challenges along the way. Presenting at events like Maker Faire may elevate stress for youth and make educators feel pressured to focus on finishing projects rather than the creative process.

As such, making programs must pay attention to the pedagogical practices impacting cultural norms in their spaces (encouraging playfulness, welcoming safety in not knowing, valuing process over product), as well as students' social dynamics. Professional development should balance supporting both youth's making processes, as well as their sociocultural interactions.

Learning from these cases, we believe there are two important areas for further research. First, considering how sociocultural dynamics impact youth persistence, we believe there should be deeper investigations into how girls' intersectional identities impact their group dynamics. For example, how did Camille's identity as a teacher's daughter and an African American ninthgrade female relate to and contrast with Jessica's identity as a White female who identified as "loving science"? If we truly want to support STEM+C learning for allyouth, explorations of the differential manifestations and impacts of institutional racism, sexism, heterosexism, ability, and classism on students in making spaces are needed. 
Second, how can data collection processes create respectful space for girls to voice the tensions they may feel in their collaborative groups or projects? Getting group composition right is important for collaboration (Kekelis, Ancheta, Heber, \& Countryman, 2005). Bringing researchers and educators together to not only design for positive group composition, but also to create opportunities where youth can name what works and doesn't work for them would be useful. Forcing students to work collaboratively can yield meaningful experiences, but for longer-term projects, it may be beneficial for youth to choose who they work with while conducting intentional check-ins where students can express what is or isn't working. Techbridge Girls has since focused on this aspect of their program, with more intention and care given to grouping students.

In conclusion, if we want youth to persist through challenging iterations in their making projects, then we must create environments that make it safe to persevere despite not always knowing the answer. These cases demonstrate how individual desire alone is not enough to inspire that persistence. The learning space's cultural norms need to embrace ways of reframing failure while building supportive relationships between learners and educators that make it worth persevering.

\section{Acknowledgments}

We would like to thank all the students at Techbridge Girls for their inspiring work. We would also like to thank: Bronwyn Bevan, Nicole Bulalacao, Angela Clabrese Barton, Mr. D, David DeLiema, Meg Escudé, Roxana Hadad, Ben Henriquez, Adam Maltese, Emily McLeod, Mike Petrich, and all our colleagues in the California Tinkering Afterschool Network.

This work was supported by the National Science Foundation (DUE-1238253/DRL-1626365) and S. D. Bechtel, Jr. Foundation under the Research + Practice Collaboratory. Opinions expressed are those of the authors and not the funding agencies.

\section{References}

Babineaux, R., \& Krumboltz, J. (2013). Fail fast, fail often: How losing can help you win. New York, NY: Penguin Group. 


\section{Reframing "Failure" in Making}

Basulto, D. (2012, May 30). The new \#Fail: Fail fast, fail early and fail often. The Washington Post. Retrieved July 10, 2015 from https://www.washingtonpost.com/blogs/innovations/post/the-newfail-fail-fast-fail-early-and-failoften/2012/05/30/gJQAKA891U_blog.html?utm_term=.46920004a9ba

Bevan, B., Ryoo, J. J., \& Shea, M. (2017). What if? Building creative cultures for STEM making and learning. After School Matters, 25, 1-8.

Blikstein, P. (2013). Digital fabrication and 'making' in education: The democratization of invention. In J. Walter-Herrmann, \& C. Büching (Eds.), FabLabs: Of machines, makers and inventors (pp 1-21). Bielefeld, Germany: Transcript.

Calabrese Barton, A., Tan, E., \& Greenberg, D. (2017). The makerspace movement: Sites of possibilities for equitable opportunities to engage underrepresented youth in STEM. Teachers College Record, $119(6), 1-44$.

Coburn, C. E., Penuel, W. R., \& Geil, K. E. (2013). Research-practice partnerships: A strategy for leveraging research for educational improvement in school districts. New York: William T. Grant Foundation. Retrieved from InformalScience.org/sites/default/ files/Research-PracticePartnerships-at-the-District-Level.pdf

Cole, M. \& Engestrom, Y. (2007). Cultural-historical approaches to designing for development. In J. Valsiner \& A. Rosa (Eds.), The Cambridge handbook of sociocultural psychology (pp. 484-506). New York, NY: Cambridge University Press.

Credé, M., Tynan, M. C., \& Harms, P. D. (2016). Much ado about grit: A meta-analytic synthesis of the grit literature. Journal of Personality and Social Psychology. Advance online publication. doi: 10.1037/pspp0000102

Dougherty, D. (2013). The maker mindset. In M. Honey, \& D.E. Kanter, (Eds.), Design, make, play: Growing the next generation of STEM innovators (pp. 7-11). New York, NY: Routledge.

Duckworth, A. L., Peterson, C., Matthews, M. D., \& Kelly, D. R. (2007). Grit: Perseverance and passion for long-term goals. Journal of Personality and Social Psychology, 92(6), 1087-1101. doi:10.1037/0022-3514.92.6.1087

Dweck, C. (2006). Mindset: The new psychology of success. New York, NY: Ballantine Books.

Dweck, C., \& Leggett, E. L. (1988). A social-cognitive approach to motivation and personality. Psychological Review, 95(2): 256-273. doi:10.1037/0033-295X.95.2.256

Erickson, F. (1998). Qualitative research methods for science education. In B. J. Fraser, \& K. G. Tobin (Eds.), International handbook of science education (pp. 1155-1173). Dordrecht, NL: Kluwer.

Glaser, B. G., \& Strauss, A. L. (1967). The discovery of grounded theory: Strategies for qualitative research. Chicago, IL: Aldine. 


\section{Reframing "Failure" in Making}

Jovanovic, J. \& King, S.S. (1998). Boys and girls in the performance-based science classroom: Who's doing the performing? American Educational Research Journal, 35(3), 477-496. doi:10.2307/1163445

Kafai, Y. B. Fields, D. A., \& Searle, K. A. (2014). Electronic textiles as disruptive designs in schools: Supporting and challenging maker activities for learning. Harvard Educational Review, 84(4), 532556. doi:10.17763/haer.84.4.46m7372370214783

Kapur, M. (2008). Productive failure. Cognition and Instruction, 26(3), 379-424. doi:10.1080/07370000802212669

Kapur, M. (2014). Productive failure in learning math. Cognitive Science, 38(5), 1008-1022. doi:10.1111/cogs. 12107

Kekelis, L. S., Ancheta, R. W., Heber, E., \& Countryman, J. (2005) Bridging differences: How social relationships and racial diversity matter in a girls' technology program. Journal of Women and Minorities in Science and Engineering, 11(3), 231-246. doi:10.1615/JWomenMinorScienEng.v11.i3.20

Kekelis, L. \& Ryoo, J. J. (April 22, 2015). The other F word: Making sense of failure and nurturing resilience. Retrieved from Corwin Connect website: http://corwin-connect.com/2015/04/theother-f-word-making-sense-of-failure-and-nurturing-resilience/

Kenney, L., McGee, P., \& Bhatnagar, K. (2012). Different, not deficient: The challenges women face in STEM fields. Journal of Technology, Management \& Applied Engineering, 28(2), 2-9.

Kohn, A. (April 8, 2014). Ten concerns about the 'let's teach them grit' fad. Washington Post; Answer Sheet. Retrieved August 31, 2015 from http://www.washingtonpost.com/blogs/answersheet/wp/2014/04/08/ten-concerns-about-the-lets-teach- them-grit-fad/

Kohn, A. (August 16, 2015). The perils of "Growth Mindset" education: Why we're trying to fix our kids when we should be fixing the system. Salon.com. Retrieved from http://wws.salon.com/2015/08/16/the_education_fad_thats_hurting_our_kids_what_you_need_t o_know_about_growth_mindset_theory_and_the_harmful_lessons_it_imparts/

Lave, J., \& Wenger, E. (1991). Situated learning: Legitimate peripheral participation. Cambridge, UK: Cambridge University Press.

Li, Y., \& Bates, T. C. (2017). Does mindset affect children's ability, school achievement, or response to challenge? Three failures to replicate. Retrieved from https://osf.io/preprints/socarxiv/tsdwy

Martin, L. (2015). The promise of the maker movement for education. Journal of Pre-College Engineering Education Research (J-PEER), 5(1), 30-39. doi:10.7771/2157-9288.1099

Martinez, S. L., \& Stager, G. (2013). Invent to learn: Making, tinkering, and engineering in the classroom. Torrance, CA: Constructing Modern Knowledge Press.

Mitchell, J. C. (1984). Typicality and the case study. In R. Ellen (Ed.). Ethnographic research: $A$ guide to general conduct (pp. 237-241). New York, NY: Academic Press. 


\section{Reframing "Failure" in Making}

McNeill, K. L., Katsh-Singer, R., \& Pelletier, P. (2015). Assessing science practices: Moving your class along a continuum. Science Scope, 39(4), 21-28.

Pollack, E. (2015). The only woman in the room. Why science is still a boys' club. Boston: Beacon Press.

Rienzo, C., Rolfe, H., \& Wilkinson, D. (2014). Changing mindsets: Evaluation report and executive summary. Report to the Education Endowment Foundation, London: EEF.

Rogoff, B. (1994). Developing understanding of the idea of communities of learners. Mind, Culture, \& Activity, 1(4): 209-229. doi:10.1080/10749039409524673

Rose, M. (May 14, 2015). Why teaching kids to have 'grit' isn't always a good thing. Washington Post; Answer Sheet. Retrieved July 1, 2015 from http://www.washingtonpost.com/blogs/answersheet/wp/2015/05/14/why-teaching-kids-to-have-grit-isnt- always-a-good-thing/

Rustin, S. (May 10, 2016). New test for 'growth mindset,' the theory that anyone who tries can succeed. The Guardian. Retrieved from https://www.theguardian.com/education/2016/may/10/growthmindset-research-uk-schools-sats

Ryoo, J. J., Bulalacao, N., Kekelis, L., McLeod, E., Henriquez, B. (2015, September). Tinkering with "failure": Equity, learning, and the iterative design process. Paper presented at FabLearn Conference, Stanford, CA.

Ryoo, J. J. \& Kekelis, L. (2016). STEM-rich and equitable making: Lessons from a museum-based research-practice partnership. ASTC Dimensions, 45-51.

Shapiro, J.R. \& Williams, A.M. (2012). The role of stereotype threats in undermining girls' and someone's performance and interest in STEM fields. Sex Roles, 66(3-4), 175-183. doi:10.1007/s11199-0110051-0

Sheridan, K., Halverson, E. R., Litts, B., Brahms, L., Jacobs-Priebe, L., \& Owens, T. (2014). Learning in the making: A comparative case study of three makerspaces. Harvard Educational Review, 84(4), 505-531. doi:10.17763/haer.84.4.brr34733723j648u

Taylor, S. J., \& Bogdan, R. (1998). Introduction to qualitative research methods: A guidebook and resources ( $3^{r d}$ ed.). New York: John Wiley \& Sons.

Vossoughi, S., \& Bevan, B. (October, 2014). Making and Tinkering: A Review of the Literature. National Research Council Committee on Out of School Time STEM: 1-55. Retrieved from http://sites.nationalacademies.org/cs/groups/dbassesite/documents/webpage/dbasse_089888.pd $f$

Vossoughi, S., Escudé, M., Kong, F., \& Hooper, P. (2013, October). Tinkering, learning \& equity in the after-school setting. Paper presented at FabLearn, Stanford, CA. Retrieved August 24, 2014 from http://fablearn.stanford.edu/2013/papers/

Vossoughi, S., Hooper, P. K., \& Escudé, M. (2016). Making through the lens of culture and power: Toward transformative visions for educational equity. Harvard Educational Review, 86(2), 206232. 
Journal of Youth Development | http://jyd.pitt.edu/ | Vol. 13 Issue 4 DOI 10.5195/jyd.2018.624

$$
\text { Reframing "Failure" in Making }
$$

Vygotsky, L. S. (1978). Mind in society: The development of higher psychological processes. Cambridge, MA: Harvard University Press.

Wertsch, J. V., del Rio, P., \& Alvarez, A. (1995). Sociocultural studies of mind. Cambridge, UK: Cambridge University Press. 